\title{
Vierte Fortbildungsveranstaltung des NipD
}

\section{Interdisziplinärer Austausch zum Thema Dermatologie}

\section{Akne - auch bei Neugeborenen möglich}

— Die Acne neonatorum zeigt sich hauptsächlich im Bereich des Gesichts. Dabei sind vor allem gerötete Papeln, Pusteln sowie vereinzelt Komedonen auffällig. Bislang

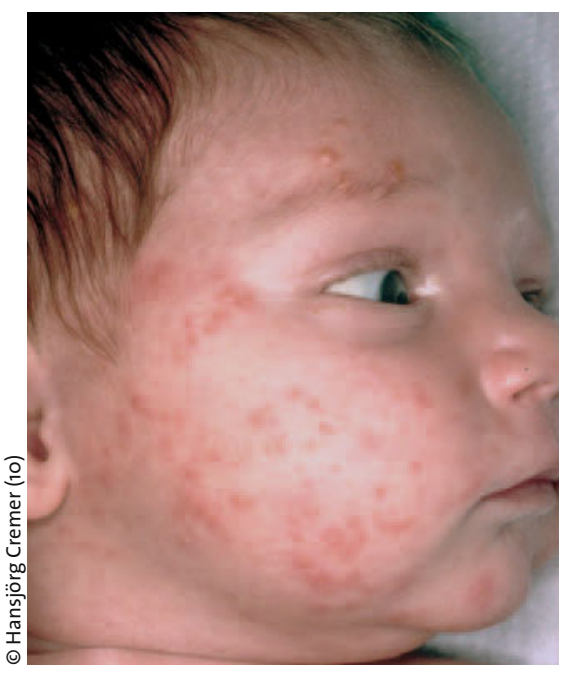

Acne neonatorum mit Papeln und Pusteln galt als Ursache die Übertragung der mütterlichen Hormone über die Plazenta. Prof. Dr. Hansjörg Cremer aus Heilbronn wies jedoch darauf hin, dass nach neueren Erkenntnissen der Abfall der mütterlichen Östrogene beim Neugeborenen nach der Geburt eine hypophysäre Gonadotropinausschüttung verursacht: Bei Mädchen werden dadurch überwiegend follikelstimulierendes Hormon (FSH) und bei Jungen luteinisierendes Hormon (LH) induziert. Dies führt etwa bei männlichen Säuglingen zu erhöhten Testosteronspiegeln in den ersten Lebensmonaten. Die Acne neonatorum, so Cremer, müsse in der Regel nicht behandelt werden. Eine tägliche Reinigung mit milder Seife und Wasser führt zu einer rascheren Rückbildung. Das Auftragen von Ölen oder Lotiones dagegen verstärkt eher das Krankheitsbild.

af

Cremer H. Hautveränderungen in der Neugeborenenperiode

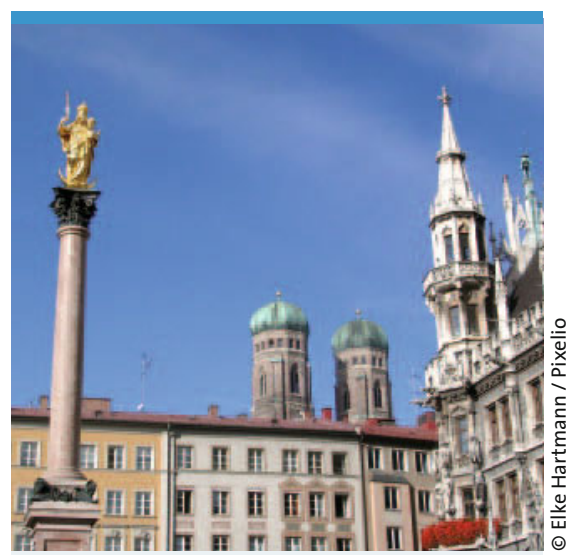

\section{Kinderdermatologie} in München

Am 28. November 2009 fand in München zum vierten Mal die Fortbildungsveranstaltung „Pädiatrische Dermatologie kompakt" statt, initiiert vom Netzwerk interdisziplinäre pädiatrische Dermatologie (NipD e.V.). Die Veranstaltung hat zum Ziel, die Zusammenarbeit von Pädiatern und Dermatologen zu fördern. Typische Hauterkrankungen wie Hämangiome und Akne standen im Fokus.

\section{Aknetherapie: Kritischer Umgang mit Antibiotika}

— In nahezu jedem Lebensalter kann Akne auftreten. Das Verständnis für die Pathogenese der Akne durch das Propionibacterium acnes, so Dr. Thomas Jansen aus Essen, habe sich grundlegend verändert. Der Erreger ist nicht der klassische Auslöser der Erkrankung, sondern ein Promotor, der chemotaktische Faktoren und extrazelluläre Enzyme bildet und vermutlich auch als Antigen wirkt. Die Reduktion der Propionibakterien durch Antibiotika spielt nur in den ersten ein bis zwei Wochen eine entscheidende
Bedeutung, danach wirken diese Substanzen antientzündlich etwa durch Hemmung der Mitose von Lymphozyten, Inhibition der Phagozytose und Verschiebung der Balance zugunsten antiinflammatorischer Zytokine.

Der Einsatz von Antibiotika in der Aknetherapie hat jedoch zu teils erschreckenden Resistenzentwicklungen geführt, erklärte Jansen. In Europa konnten bei über $60 \%$ der Patienten Propionibakterienstämme isoliert werden, die resistent gegenüber
Erythromycin waren. Eine topische Therapie mit Erythromycin oder Clindamycin verändert auch signifikant die Hautflora, weshalb diese Antibiotika nicht als Monotherapeutika eingesetzt werden sollten. Eine Kombination mit topischen Retinoiden oder Benzoylperoxid verkürzt den Therapieverlauf. Bei Acne comedonica und in der Erhaltungstherapie sind Antibiotika nicht indiziert. Jansen empfahl, bei der Behandlung der Akne vermehrt antibiotikafreie Topika (Retinoide und Benzoylperoxid, z.B. Epiduo ${ }^{\circledR}$ ) einzusetzen. af

Jansen T. Aktuelle Aspekte der Aknetherapie 